\title{
Pilot study indicate role of preferentially transmitted monoamine oxidase gene variants in behavioral problems of male ADHD probands
}

Arijit Karmakar', Rishov Goswami' ${ }^{1}$, Tanusree Saha', Subhamita Maitra', Anirban Roychowdhury², Chinmay Kumar Panda ${ }^{2}$, Swagata Sinha', Anirban Ray ${ }^{3}$, Kochupurackal P. Mohanakumar ${ }^{4,5}$, Usha Rajamma ${ }^{1,5}$ and Kanchan Mukhopadhyay ${ }^{1 *}$ (D)

\begin{abstract}
Background: Attention deficit hyperactivity disorder (ADHD) is an etiologically complex childhood onset neurobehavioral disorder characterized by age-inappropriate inattention, hyperactivity, and impulsivity. Symptom severity varies widely and boys are diagnosed more frequently than girls. ADHD probands were reported to have abnormal transmissions of dopamine, serotonin, and/or noradrenaline. Monoamine oxidase A (MAOA) and B (MAOB), mitochondrial outer membrane bound two isoenzymes, mediate degradation of these neurotransmitters and thus regulating their circulating levels. Case-control analyses in different populations, including Indians, suggested involvement of $M A O A$ and $M A O B$ genes in the etiology of ADHD. Due to high heritability rate of ADHD, we tested familial transmission of MAOA and MAOB variants to ADHD probands in 190 nuclear families having ADHD probands from Indo-Caucasoid ethnicity.
\end{abstract}

Methods: Subjects were recruited following the Diagnostic and Statistical Manual of Mental Disorders-4th edition (DSM-IV). Appropriate scales were used for measuring the behavioral traits in probands. Genotyping was performed through PCR-based amplification of target sites followed by DNA-sequencing and/or gel-electrophoresis. Data obtained were analyzed by family based statistical methods.

Results: Out of 58 variants present in the analyzed sites only 15 were found to be polymorphic (30 bp-uVNTR, rs5906883, rs1465107, rs1465108, rs5905809, rs5906957, rs6323, rs 1137070 from MAOA and rs4824562, rs56220155, rs 2283728, rs2283727, rs3027441, rs6324, rs3027440 from MAOB). Statistically significant maternal transmission of alleles to male probands was observed for MAOA rs5905809 ' $G$ ' $(p=0.04)$, rs5906957 ' $A$ ' $(p=0.04)$, rs6323 ' $G$ ' ( $p=0$. $0001)$ and MAOB rs56220155 ' $A$ ' $(p=0.002), r s 2283728{ }^{\prime} C$ ' $(p=0.0008)$, rs $2283727^{\prime} C$ ' $(p=0.0008)$, rs3027441 ' $T$ $(p=0.003)$, rs6324 ' $C$ ' $(p=0.003)$, rs3027440 ' $T$ ( $p=0.0002$ ). Significantly preferential maternal transmissions of different haplotype combinations to male probands were also noticed $(p<0.05)$, while female probands did not reveal such transmission bias. Behavioral traits of male probands exhibited significant association with gene variants. Age of the mother at pregnancy also revealed association with risk variants of male probands.

Conclusions: It may be inferred that the MAOA and MAOB variants may contribute to the etiology of ADHD in the Indo-Caucasoid population and could be responsible for higher occurrence of ADHD in the boys.

Keywords: ADHD, MAOA, MAOB, Genotyping, Maternal transmission, Behavioral trait, Maternal age, Linkage disequilibrium, Indo-Caucasoid population

\footnotetext{
* Correspondence: kanchanmvk@yahoo.com

'Manovikas Biomedical Research and Diagnostic Centre, 482, Madudah, Plot:

1-24, Sector-J, Manovikas Kendra, E.M. Bypass, Kolkata 700 107, India

Full list of author information is available at the end of the article
} 


\section{Background}

Attention deficit hyperactivity disorder (ADHD) is an etiologically complex neurobehavioral disorder, diagnosed mostly during early childhood [1]. The disorder is highly prevalent throughout the world, including India, and boys are more frequently diagnosed with ADHD as compared to girls [2-6]. Age-inappropriate persistent and pervasive symptoms of inattention, hyperactivity, and impulsivity [1] often lead to impairments in academic performances as well as social life $[7,8]$. Other psychiatric conditions, frequently detected as co-morbidity in subjects with ADHD, may make the situation worse $[9,10]$. Thus an early diagnosis, leading to early intervention, becomes crucial for successful management.

Being a multi-factorial disorder with almost $76 \%$ heritability $[11,12]$, ADHD is believed to have significant influence of multiple gene variants [13-16]. Candidate genes involved in the regulation of dopamine, serotonin, and noradrenalin were widely studied in ADHD subjects since behavioral traits are regulated by these neurotransmitters $[13,15,17,18]$ and both dopaminergic [15, 19-21] and serotonergic [22] transmissions revealed significant impact on behavioral as well as cognitive features.

Two flavin containing isoenzymes, monoamine oxidase A (MAOA) and B (MAOB), help in the deamination of biogenic amines from both endogenous and exogenous sources $[23,24]$. Both the enzymes are localized in the mitochondrial outer membrane and metabolize dopamine, tyramine, and tryptamine with equal efficiency [25-27]. Comparative analysis also revealed that while MAOA preferentially deaminates serotonin, noradrenalin, adrenaline, and melatonin, preferred substrates for MAOB are phenylethylamine (PEA) and benzylamine [25-27].

In men of a Dutch family, MAOA deficiency showed association with aggressive behavior [28] and deletion of the MAOA gene showed association with aggressive phenotypes across species [29-31]. MAOA also exhibited association with vulnerability to disorders of attention and impulsivity [32] and a possible link between predisposition to novelty seeking [33], making the $M A O A$ gene, encoding for the MAOA enzyme, a prime candidate for ADHD [31, 32, 34, 35].

MAOB was also postulated to regulate impulsivity, attention and vulnerability to ADHD through metabolism of dopamine, although to a lesser extent as compared to MAOA [20, 32]. Correlation of platelet MAOB activity with sensation seeking and other behavioral abnormalities have also been reported [36, 37]. Negative emotionality of healthy volunteers showed association with $M A O B$ polymorphisms [38]. However, platelet MAOB activity failed to correlate with brain MAOB activity, thus questioning the usefulness of MAOB as a marker for psychiatric behavior [39].
Proportional analysis in patients revealed that the absence of MAOA leads to greater change in neurotransmitter metabolism than absence of MAOB [40]. While $M A O A$ knockout mice showed increased levels of serotonin, norepinephrine and dopamine in the brain [41], only level of PEA was increased in $M A O B$ knockout mice [42]. MAOA and MAOB double knockout mice showed an increased reactivity to stress [30] and increased levels of serotonin, norepinephrine, dopamine, and PEA in the brain to a much greater degree than in either $M A O A$ or $M A O B$ single knockout mice [43].

In this backdrop of information, both $M A O A$ and $M A O B$ genes, located on the $\mathrm{X}$ chromosome [26], were considered to contribute to the etiology of ADHD [31, 32, 34, 44-46]. However, worldwide only a few $M A O A$ and $M A O B$ gene variants were studied and the data obtained were neither consistent nor conclusive [31, 35, 37, 44-47]. Our population-based analysis on $58 M A O$ gene variants revealed association of a number of variants with ADHD $[48,49]$. Due to high heritability of ADHD traits, in the present study all these variants were explored to identify familial transmission pattern. Additionally, based on the $\mathrm{X}$-chromosomal location of $M A O A$ and $M A O B$ [46], we have performed gender based stratified analysis to identify whether any variant is preferentially transmitted to the probands and thus may have a role in the gender bias often reported in ADHD.

\section{Methods}

\section{Subject recruitment}

A total of 190 ADHD probands (166 males and 24 females) and their biological parents, of Indo-Caucasoid ethnicity from the eastern India, were recruited from the out-patient department of Manovikas Kendra Rehabilitation and Research Institute for the Handicapped, Kolkata, India. Diagnosis was performed by child psychiatrist and clinical psychologist following the Diagnostic and Statistical Manual of Mental Disorders-4th edition (DSM-IV) criteria [50]. $74.74 \%$ of the recruited ADHD probands were of the combined subtype, while inattentive and hyperactive-impulsive subtypes were of $13.68 \%$ and $11.58 \%$ respectively. Mean age of the ADHD probands was $8.01 \pm 0.22$ years (Mean \pm SE). Psychological evaluation was done through - the revised Conners' Parents Rating Scale (CPRS-R) [51] and Wechsler Intelligence Scale for Children $>5$ yrs. [52] / Developmental Screening Test [53] for children $<5$ yrs. for the inattentionhyperactivity level and intelligent quotient (IQ)/ developmental quotient (DQ) status respectively. Oppositional defiant disorder (ODD) and conduct problems of ADHD probands were assessed using the DSM-IV score and Parental Account of Children's Symptoms (PACS) score respectively. Probands with any other neuropsychiatric disorders, mental retardation (IQ $\leq 70)$ 
including Down syndrome and Fragile- $\mathrm{X}$ syndrome, pervasive developmental disorder were excluded from the study. Among 166 male ADHD probands 133 were trios, 25 were duos (6 excluding mother and 19 excluding father) and 8 were single probands. Among the 24 female probands, 15 were trios, 6 were duos (having mother only) and 3 were single probands. Informed written consent was obtained from guardians / biological parents of the probands participating in the study and the protocol was approved by the Institutional Human Ethical Committee.

\section{Genotyping}

Peripheral blood of the study participants was collected by a trained phlebotomist and used for genomic DNA preparation following the standard protocol [54]. The target regions were amplified via polymerase chain reaction (PCR) using oligonucleotides designed in the lab using the Primer3 software [55] and the amplicons were utilized for genotyping the samples either through gel electrophoresis or using Sanger sequencing by capillary electrophoresis method [56]. For sequence analysis of the amplicons, Applied Biosystems 3130 Genetic Analyzer was used [48, 49]. Chromatograms were also analyzed manually and for the identification of heterozygous SNPs, $>25 \%$ base calling was accepted. Detailed analytic protocols for PCR amplification and genotyping were published earlier $[48,49]$.

\section{Statistical analyses of data}

Genotypic counts of only the female subjects (i.e. female ADHD probands and mother of the probands) were used for analyzing the Hardy-Weinberg equilibrium [57], since the MAO genes are located on the X-chromosome. For the same reason, family-based analysis on male ADHD probands was carried out considering only the maternal transmission. Paternal transmission was considered for female ADHD probands only. Haplotype-based haplotype relative risk (HHRR) analysis [58] was performed using UNPHASED v 3.1.5 [59] to identify allelic and haplotypic transmission patterns. Correction for multiple testing was done while running the UNPHASED at 1000-fold iteration. Relative risk or Risk ratio for variants showing significant association was calculated online [60]. Pair-wise linkage disequilibrium (LD) between the variants was calculated using the Haploview program version 4.2 [61], considering male and female probands separately. Since $M A O$ genes are X-linked, for female probands the parental genotype data and for male probands only the maternal genotype data were used for comparative analysis.

\section{Stratified analysis on behavioral traits, age-of-onset, and maternal age at pregnancy}

Based on the CPRS-R, respective 'T scores' for oppositional behavior, cognitive problems / inattention, hyperactivity, and ADHD index were obtained for ADHD probands $(N=166)$. DSM-IV score for ODD trait and PACS for conduct problems of ADHD probands were also obtained. CPRS-R 'T scores' ranged between 38 to 90 while DSM-IV scores and PACS scores ranged between 0 to 36 and 0 to 90 respectively. Behavioral traits/scores of ADHD probands were utilized for genetic association analysis. Male probands were divided into two sub-groups based on the presence/absence of the derived allele of each variant. Allelic association with behavioral scores was analyzed using Student's t-test [62] in the presence of normal distribution of data and equal variances in the two comparing groups. Age of the male ADHD probands at the time of onset of the disorder were used for stratified analysis; probands with detectable symptoms at an age $\leq 7$ years $(N=109)$ were considered under 'early onset,', while those with detectable symptoms after 7 years $(N=57)$ were classified under the 'late onset'. Association of alleles with age-of-onset of ADHD in the male probands was calculated using the chisquare test [62]. To calculate the impact of maternal age at pregnancy, allelic frequencies of male probands born to mothers $\leq 26$ years $(N=71)$ were compared to that of male probands born to mothers at $>26$ years $(N=81)$ of age using the chi-square test [62]. As the number of female probands was limited, association of variants with behavioral scores, age-of-onset of ADHD, and maternal age at pregnancy were not analyzed.

\section{Results}

Out of 58 variants present in the analyzed sites, only 15 (30 bp-uVNTR, rs5906883, rs1465107, rs1465108, rs5905809, rs5906957, rs6323, rs1137070 from $M A O A$ and rs4824562, rs56220155, rs2283728, rs2283727, rs3027441, rs6324, rs3027440 from $M A O B$ ) were found to be polymorphic. All the studied polymorphic variants followed the HardyWeinberg equilibrium in the female subjects, i.e. female ADHD probands and mother of the ADHD probands (Additional file 1). Family-based analysis showed statistically significant maternal over-transmission of $M A O A$ rs5905809 ' $G$ ' $(p=0.04)$, rs5906957 ' $A$ ' $(p=0.04)$ and rs6323 ' $G$ ' $(p=0.0001)$ alleles and $M A O B$ rs56220155 ' $A$ ' $(p=0.002), \operatorname{rs} 2283728$ ' $C$ ' $(p=0.0008), \operatorname{rs} 2283727$ ' $C$ ' $(p=0.0008), \operatorname{rs} 3027441{ }^{\prime} T(p=0.003), \operatorname{rs} 6324{ }^{\circ} C$ ' $(p=0.003)$ and $\operatorname{rs} 3027440{ }^{\prime} T(p=0.0002)$ alleles to the male probands (Table 1). The relative risk was also statistically significant for $M A O A$ rs5905809 ' $G$ ', rs5906957 ' $A$ ' and rs6323 ' $G$ ' and all the $M A O B$ variants excepting for rs4824562 (Table 1). No such parental bias in transmissions was observed in the female probands (Additional file 2). Several intra-genetic as well as inter-genetic haplotypic combinations also showed statistically significant maternal overtransmission to the male probands $(p \leq 0.05)$ (Table $2 \&$ Additional file 3$)$. Most significantly over-transmitted $(p=0.002)$ intra-genetic haplotypes of MAOA were 
Table 1 Maternal allelic transmission to male ADHD probands

\begin{tabular}{|c|c|c|c|c|c|c|}
\hline Genes & Variants & Alleles & Transmitted & Non-transmitted & Chi-square ( $p$-value) & Relative risk (95\% confidence interval) \\
\hline \multirow[t]{16}{*}{$\overline{M A O A}$} & \multirow[t]{2}{*}{30 bp-uVNTR } & $3 R$ & 0.68 & 0.65 & \multirow[t]{2}{*}{$0.37(0.54)$} & \multirow[t]{2}{*}{-} \\
\hline & & $4 R$ & 0.32 & 0.35 & & \\
\hline & \multirow[t]{2}{*}{ rs5906883 } & $A$ & 0.67 & 0.64 & \multirow[t]{2}{*}{$0.36(0.55)$} & \multirow[t]{2}{*}{-} \\
\hline & & C & 0.33 & 0.36 & & \\
\hline & \multirow[t]{2}{*}{ rs1465107 } & G & 0.31 & 0.39 & \multirow[t]{2}{*}{$2.44(0.12)$} & \multirow[t]{2}{*}{-} \\
\hline & & $A$ & 0.69 & 0.61 & & \\
\hline & \multirow[t]{2}{*}{ rs1465108 } & $A$ & 0.69 & 0.61 & \multirow[t]{2}{*}{$2.44(0.12)$} & \multirow[t]{2}{*}{-} \\
\hline & & G & 0.31 & 0.39 & & \\
\hline & \multirow[t]{2}{*}{ rs5905809 } & C & 0.33 & 0.44 & \multirow[t]{2}{*}{$4.03(\mathbf{0 . 0 4})$} & \multirow[t]{2}{*}{$1.20(1.00-1.44)$} \\
\hline & & G & 0.67 & 0.56 & & \\
\hline & \multirow[t]{2}{*}{ rs5906957 } & $A$ & 0.67 & 0.56 & \multirow[t]{2}{*}{$4.03(\mathbf{0 . 0 4})$} & \multirow[t]{2}{*}{$1.20(1.00-1.44)$} \\
\hline & & G & 0.33 & 0.44 & & \\
\hline & \multirow[t]{2}{*}{ rs6323 } & $T$ & 0.24 & 0.45 & \multirow[t]{2}{*}{$15.15(\mathbf{0 . 0 0 0 1})$} & \multirow[t]{2}{*}{$1.38(1.17-1.63)$} \\
\hline & & G & 0.76 & 0.55 & & \\
\hline & \multirow[t]{2}{*}{ rs1137070 } & $C$ & 0.32 & 0.41 & \multirow[t]{2}{*}{$2.40(0.12)$} & \multirow[t]{2}{*}{-} \\
\hline & & $T$ & 0.68 & 0.59 & & \\
\hline \multirow[t]{14}{*}{$M A O B$} & \multirow[t]{2}{*}{ rs4824562 } & $A$ & 0.80 & 0.73 & \multirow[t]{2}{*}{$2.23(0.14)$} & \multirow[t]{2}{*}{ - } \\
\hline & & G & 0.20 & 0.27 & & \\
\hline & \multirow[t]{2}{*}{ rs56220155 } & G & 0.26 & 0.43 & $9.16(\mathbf{0 . 0 0 2})$ & $1.29(1.09-1.52)$ \\
\hline & & $A$ & 0.74 & 0.57 & & \\
\hline & rs2283728 & $T$ & 0.19 & 0.36 & $11.26(\mathbf{0 . 0 0 0 8})$ & $1.27(1.10-1.46)$ \\
\hline & & C & 0.81 & 0.64 & & \\
\hline & rs2283727 & C & 0.81 & 0.64 & $11.26(\mathbf{0 . 0 0 0 8})$ & $1.27(1.10-1.46)$ \\
\hline & & $A$ & 0.19 & 0.36 & & \\
\hline & rs3027441 & C & 0.20 & 0.35 & $8.86(\mathbf{0 . 0 0 3})$ & $1.23(1.07-1.42)$ \\
\hline & & $T$ & 0.80 & 0.65 & & \\
\hline & rs6324 & C & 0.80 & 0.65 & $8.86(\mathbf{0 . 0 0 3})$ & $1.23(1.07-1.42)$ \\
\hline & & $T$ & 0.20 & 0.35 & & \\
\hline & rs3027440 & $T$ & 0.86 & 0.68 & $13.67(\mathbf{0 . 0 0 0 2})$ & $1.26(1.11-1.43)$ \\
\hline & & C & 0.14 & 0.32 & & \\
\hline
\end{tabular}

Statistically significant differences are presented in bold

Table 2 Intra- and inter-genetic haplotypes transmitted most significantly to male ADHD probands from mothers

\begin{tabular}{llllll}
\hline Combinations & Variants & Haplotype & Transmitted & Non-transmitted & Chi-square $(p$-value) \\
\hline Intra genetic in MAOA & rs5906883-rs6323 & C-G & 0.15 & 0.05 & $9.47(\mathbf{0 . 0 0 2})$ \\
& rs5905809-rs6323 & $G-G$ & 0.62 & 0.44 & $9.63(\mathbf{0 . 0 0 2})$ \\
& rs5906957-rs6323 & $A-G$ & 0.62 & 0.44 & $9.63(\mathbf{0 . 0 0 2})$ \\
Inter genetic between MAOA and MAOB & rs6323-rs2283727 & G-C & 0.58 & 0.34 & $18.15(\mathbf{2 . 0 5 E}-\mathbf{0 5})$ \\
& rs6323-rs2283728 & G-C & 0.58 & 0.34 & $18.15(\mathbf{2 . 0 5 E}-\mathbf{0 5})$ \\
Intra genetic in MAOB & rs3027440-rs2283727 & T-C & 0.80 & 0.57 & $18.55(\mathbf{1 . 6 6 E}-\mathbf{0 5})$ \\
& rs3027440-rs2283728 & T-C & 0.80 & 0.57 & $18.55(\mathbf{1 . 6 6 E}-\mathbf{0 5})$ \\
\hline
\end{tabular}


rs5906883-rs6323 'C-G', rs5905809-rs6323 'G-G', and rs5906957-rs6323 'A-G' (Table 2). Most significantly over-transmitted ( $p=1.66 \mathrm{E}-05)$ intra-genetic haplotypes of $M A O B$ were rs3027440-rs2283727 ' $T-C$ ' and rs3027440-rs2283728 ' $T$ - $C$ ' (Table 2). Inter-genetic haplotype combinations, between $M A O A$ and $M A O B$, showing over-transmission ( $p=2.05 \mathrm{E}-05)$ were rs6323rs2283727 ' $G-C$ ' and rs6323-rs2283728 ' $G-C$ ' (Table 2). Preferential non-transmission $(p \leq 0.05)$ of several haplotypes were also noticed (Additional file 4) in the male probands. No such significant biased parental transmissions of haplotypes were observed in the female probands (Additional file 5).

In the male ADHD probands, intra-genetic pair-wise LDs for $M A O A$ and $M A O B$ variants were found to be same as reported earlier [48, 49]. Inter-genetic pair-wise analysis revealed strong $\mathrm{LD}$ of $M A O A$ rs6323 with $M A O B$ rs3027440, rs6324, rs3027441, rs2283727, rs2283728, and rs56220155 in the male probands (Fig. 1a, Additional file 6). In mothers of the male probands, all the variants from $M A O A$ gene were found to be in pair-wise LDs with each other (Fig. 1b, Additional file 6). Complete pair-wise LDs
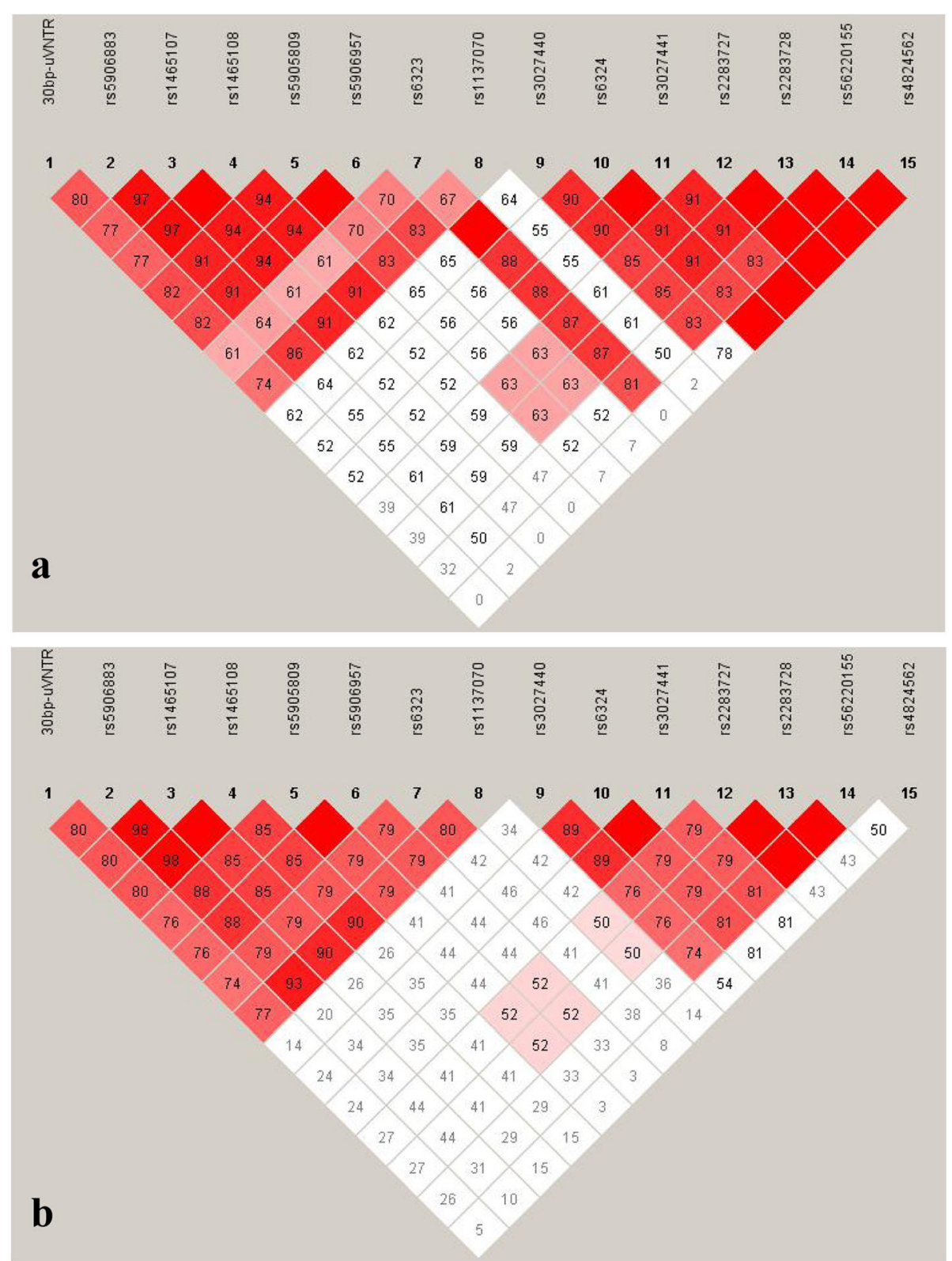

Fig. 1 Plot of pair-wise linkage disequilibrium (LD) between the polymorphic variants from MAOA and MAOB genes in a. Male ADHD cases; b. Mothers of the male ADHD cases. Diamonds without numbers represent $D^{\prime}$ values of 1.0; all numbers represent the $D^{\prime}$ value expressed as a percentile. $D^{\prime}$ is a measure of the frequency of association of alleles at 2 loci 
were found between rs1465107 and rs1465108; and rs5905809 and rs5906957 respectively (Fig. 1b, Additional file 6). In the $M A O B$, all the variants, except rs4824562, were found to be in strong pair-wise LDs with each other (Fig. 1b, Additional file 6). Complete pair-wise LDs were found between rs6324 and rs3027441; and rs2283727 and rs2283728 respectively (Fig. 1b, Additional file 7). Strong pair-wise LDs of rs56220155 with rs2283727 and rs2283728 respectively were also observed (Fig. 1b, Additional file 6). In the female ADHD probands, no inter-genetic pair-wise LDs were observed (Fig. 2a,
Additional file 6). Intra-genetic pair-wise LDs were found to be same as reported earlier [48, 49]. In the group of parents of the female probands all the variants from $M A O A$ gene, except $30 \mathrm{bp}-\mathrm{uVNTR}$ and rs1137070, were found to be in pair-wise LDs with each other (Fig. 2b, Additional file 6). Complete pair-wise LDs were found between rs1465107 and rs1465108; and rs5905809 and rs5906957 respectively (Fig. 2b, Additional file 6). Strong pair-wise LDs of rs5906883 with rs1465107 and rs1465108 respectively were observed (Fig. 2b, Additional file 6). Strong pair-wise LDs of rs6323 with
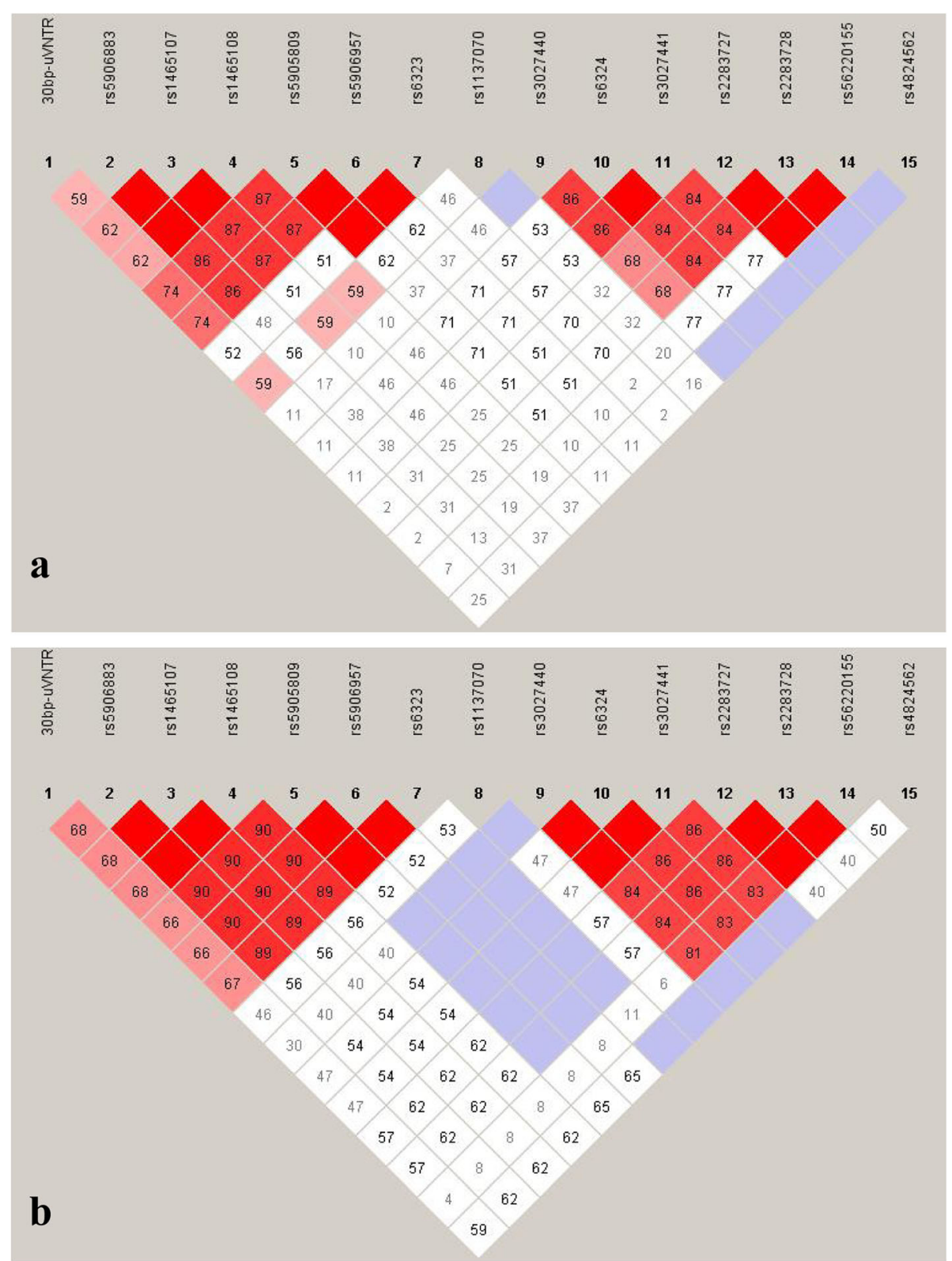

Fig. 2 Plot of pair-wise linkage disequilibrium (LD) between the polymorphic variants from MAOA and MAOB genes in a. Female ADHD cases; b. Parents of the female ADHD cases. Diamonds without numbers represent $D^{\prime}$ values of 1.0; all numbers represent the $D^{\prime}$ value expressed as a percentile. $D^{\prime}$ is a measure of the frequency of association of alleles at 2 loci 
rs5905809 and rs5906957 respectively were also observed (Fig. 2b, Additional file 6). From $M A O B$ gene, all the variants, except rs4824562, were found to be in strong pairwise LDs with each other (Fig. 2b, Additional file 6). Complete pair-wise LDs were found between rs6324 and rs3027441; and rs2283727 and rs2283728 respectively (Fig. 2b, Additional file 6). Strong pair-wise LDs of rs3027440 with rs6324 and rs3027441 respectively were observed (Fig. 2b, Additional file 6). Strong pair-wise LDs of rs56220155 with rs2283727 and rs2283728 respectively were also noticed (Fig. 2b, Additional file 6).

Behavioral traits were calculated by obtaining Mean \pm standard error (SE). CPRS- $\mathrm{R}$ 'T scores' obtained were $62.81 \pm 1.23$ for oppositional behavior, $72.38 \pm 0.79$ for cognitive problems / inattention, $74.50 \pm 0.99$ for hyperactivity, and 71.74 \pm 0.68 for ADHD index. DSMIV scores for ODD trait was $15.05 \pm 0.85$ and PACS scores for conduct problems was $16.77 \pm 1.19$. Male ADHD probands having rs6323 ' $G$ ' allele showed statistically significant higher mean ' $\mathrm{T}$ score' for hyperactivity and ADHD index as compared to those with the ' $T$ ' allele (Table 3 ). Significantly higher mean 'DSM-IV score' for ODD trait was also noticed in the male ADHD probands having rs1137070 ' $C$ ' allele as compared to the male probands having the ' $T$ ' allele (Table 3). $M A O B$ rs2283728 ' $T$ ' and rs2283727 ' $A$ ' showed statistically

Table 3 Analysis of association between alleles \& ADHD associated trait scores of male ADHD probands

\begin{tabular}{|c|c|c|c|c|c|c|c|c|c|c|}
\hline \multirow[t]{2}{*}{ Genes } & \multirow[t]{2}{*}{ Variants } & \multirow[t]{2}{*}{ Alleles } & \multicolumn{2}{|c|}{$\begin{array}{l}\text { T scores' for cognitive } \\
\text { problems / inattention }\end{array}$} & \multicolumn{2}{|l|}{$\begin{array}{l}\text { 'T scores' for } \\
\text { hyperactivity }\end{array}$} & \multicolumn{2}{|l|}{$\begin{array}{l}\text { T scores' for } \\
\text { ADHD index }\end{array}$} & \multicolumn{2}{|l|}{$\begin{array}{l}\text { DSM-IV scores } \\
\text { for ODD trait }\end{array}$} \\
\hline & & & Mean \pm SE & $p$ & Mean \pm SE & $p$ & Mean \pm SE & $p$ & Mean \pm SE & $p$ \\
\hline \multirow[t]{16}{*}{$M A O A$} & 30 bp-uVNTR & $3 R$ & $71.90 \pm 1.03$ & 0.26 & $75.16 \pm 1.23$ & 0.15 & $71.27 \pm 0.83$ & 0.29 & $14.75 \pm 1.10$ & 0.32 \\
\hline & & $4 R$ & $70.77 \pm 1.37$ & & $72.93 \pm 1.74$ & & $70.45 \pm 1.19$ & & $15.68 \pm 1.76$ & \\
\hline & rs5906883 & $A$ & $72.26 \pm 1.01$ & 0.11 & $75.34 \pm 1.27$ & 0.11 & $71.48 \pm 0.84$ & 0.17 & $14.42 \pm 1.06$ & 0.17 \\
\hline & & $C$ & $70.15 \pm 1.42$ & & $72.70 \pm 1.63$ & & $70.11 \pm 1.16$ & & $16.32 \pm 1.84$ & \\
\hline & rs1465107 & G & $71.14 \pm 1.47$ & 0.37 & $72.74 \pm 1.71$ & 0.12 & $70.51 \pm 1.21$ & 0.31 & $16.11 \pm 1.80$ & 0.21 \\
\hline & & $A$ & $71.71 \pm 1.00$ & & $75.22 \pm 1.23$ & & $71.24 \pm 0.83$ & & $14.53 \pm 1.08$ & \\
\hline & rs1465108 & $A$ & $71.71 \pm 1.00$ & 0.37 & $75.22 \pm 1.23$ & 0.12 & $71.24 \pm 0.83$ & 0.31 & $14.53 \pm 1.08$ & 0.21 \\
\hline & & G & $71.14 \pm 1.47$ & & $72.74 \pm 1.71$ & & $70.51 \pm 1.21$ & & $16.11 \pm 1.80$ & \\
\hline & rs5905809 & $C$ & $70.17 \pm 1.37$ & 0.12 & $72.24 \pm 1.60$ & 0.06 & $69.83 \pm 1.13$ & 0.10 & $16.21 \pm 1.80$ & 0.19 \\
\hline & & G & $72.24 \pm 1.03$ & & $75.58 \pm 1.27$ & & $71.63 \pm 0.85$ & & $14.47 \pm 1.08$ & \\
\hline & rs5906957 & $A$ & $72.24 \pm 1.03$ & 0.12 & $75.58 \pm 1.27$ & 0.06 & $71.63 \pm 0.85$ & 0.10 & $14.47 \pm 1.08$ & 0.19 \\
\hline & & G & $70.17 \pm 1.37$ & & $72.24 \pm 1.60$ & & $69.83 \pm 1.13$ & & $16.21 \pm 1.80$ & \\
\hline & rs6323 & $T$ & $69.48 \pm 1.62$ & 0.08 & $70.88 \pm 2.12$ & 0.02 & $69.00 \pm 1.34$ & 0.04 & $15.35 \pm 2.11$ & 0.43 \\
\hline & & G & $72.20 \pm 0.95$ & & $75.60 \pm 1.12$ & & $71.67 \pm 0.78$ & & $14.95 \pm 1.02$ & \\
\hline & rs1137070 & $C$ & $70.35 \pm 1.46$ & 0.15 & $73.00 \pm 1.66$ & 0.15 & $70.22 \pm 1.18$ & 0.20 & $17.32 \pm 1.77$ & 0.04 \\
\hline & & $T$ & $72.15 \pm 1.00$ & & $75.17 \pm 1.26$ & & $71.42 \pm 0.83$ & & $13.91 \pm 1.07$ & \\
\hline \multirow[t]{14}{*}{$M A O B$} & rs4824562 & $A$ & $71.29 \pm 0.95$ & 0.29 & $73.79 \pm 1.10$ & 0.11 & $70.59 \pm 0.77$ & 0.12 & $14.88 \pm 1.04$ & 0.35 \\
\hline & & G & $72.44 \pm 1.65$ & & $76.85 \pm 2.41$ & & $72.59 \pm 1.43$ & & $15.81 \pm 2.20$ & \\
\hline & rs56220155 & $G$ & $72.08 \pm 1.36$ & 0.34 & $76.86 \pm 1.81$ & 0.07 & $72.67 \pm 1.15$ & 0.07 & $13.82 \pm 1.40$ & 0.21 \\
\hline & & $A$ & $71.31 \pm 1.02$ & & $73.50 \pm 1.19$ & & $70.38 \pm 0.82$ & & $15.51 \pm 1.17$ & \\
\hline & rs2283728 & $T$ & $72.25 \pm 1.42$ & 0.32 & $77.79 \pm 1.63$ & 0.04 & $73.04 \pm 1.25$ & 0.06 & $13.73 \pm 1.57$ & 0.25 \\
\hline & & $C$ & $71.33 \pm 0.98$ & & $73.51 \pm 1.18$ & & $70.45 \pm 0.79$ & & $15.35 \pm 1.09$ & \\
\hline & rs2283727 & $C$ & $71.33 \pm 0.98$ & 0.32 & $73.51 \pm 1.18$ & 0.04 & $70.45 \pm 0.79$ & 0.06 & $15.35 \pm 1.09$ & 0.25 \\
\hline & & $A$ & $72.25 \pm 1.42$ & & $77.79 \pm 1.63$ & & $73.04 \pm 1.25$ & & $13.73 \pm 1.57$ & \\
\hline & rs3027441 & $C$ & $74.31 \pm 1.60$ & 0.04 & $76.83 \pm 1.58$ & 0.10 & $73.72 \pm 1.27$ & 0.02 & $14.15 \pm 1.74$ & 0.34 \\
\hline & & $T$ & $70.74 \pm 0.95$ & & $73.74 \pm 1.20$ & & $70.23 \pm 0.78$ & & $15.23 \pm 1.07$ & \\
\hline & rs6324 & $C$ & $70.74 \pm 0.95$ & 0.04 & $73.74 \pm 1.20$ & 0.10 & $70.23 \pm 0.78$ & 0.02 & $15.23 \pm 1.07$ & 0.34 \\
\hline & & $T$ & $74.31 \pm 1.60$ & & $76.83 \pm 1.58$ & & $73.72 \pm 1.27$ & & $14.15 \pm 1.74$ & \\
\hline & rs3027440 & $T$ & $71.08 \pm 0.90$ & 0.12 & $73.77 \pm 1.14$ & 0.08 & $70.57 \pm 0.76$ & 0.08 & $14.90 \pm 1.06$ & 0.34 \\
\hline & & $C$ & $73.73 \pm 2.00$ & & $77.64 \pm 1.83$ & & $73.14 \pm 1.45$ & & $16.00 \pm 1.68$ & \\
\hline
\end{tabular}


significant association with higher mean ' $\mathrm{T}$ score' for hyperactivity in the male ADHD probands in comparison to probands having the ' $C$ ' alleles of the respective variants (Table 3). Significantly higher mean 'T score' for cognitive problems / inattention and ADHD index were also noticed in the male ADHD probands having rs3027441 ' $C$ ' and rs6324 ' $T$ ' alleles than the male ADHD probands having ' $T$ ' and ' $C$ ' alleles of the respective variants (Table 3). No significant association between ' $T$ scores' for oppositional behavior and PACS scores for conduct problems were noticed (Additional file 7). Age of onset of ADHD in male probands also failed to show any significant association (Additional file 8).

Stratified analysis revealed higher occurrence of $M A O A$ 30 bp-uVNTR 3-repeat (3R), rs6323 ' $G$ ', and rs1137070 ' $T$ ' variants in the male ADHD probands (Table 4) born to younger mothers (maternal age at pregnancy $\leq 26$ years). Significant risk of association of these variants was also evident from higher relative risk (Table 4). $M A O B$ variants failed to show any statistically significant difference (Table 4).

\section{Discussion}

Studies on human emphasized a role of MAOA in behavioral attributes, as it is the prime enzyme degrading serotonin, a known regulator of human behavior [63]. Nevertheless, MAOA and MAOB equally degrades dopamine, another monoamine neurotransmitter which also regulates human behavior $[64,65]$ and interplays with the

Table 4 Analysis of association between maternal age at pregnancy and MAO variants of male ADHD probands

\begin{tabular}{|c|c|c|c|c|c|c|}
\hline Genes & Variants & Alleles & $\leq 26 \mathrm{yrs}$ & $>26 \mathrm{yrs}$ & Chi-square ( $p$-value) & Relative risk (95\% confidence interval) \\
\hline \multirow[t]{16}{*}{$M A O A$} & \multirow[t]{2}{*}{30 bp-uVNTR } & $3 R$ & 0.76 & 0.61 & \multirow[t]{2}{*}{$4.03(\mathbf{0 . 0 5})$} & \multirow[t]{2}{*}{$1.26(1.01-1.57)$} \\
\hline & & $4 R$ & 0.24 & 0.39 & & \\
\hline & \multirow[t]{2}{*}{ rs5906883 } & $A$ & 0.73 & 0.61 & \multirow[t]{2}{*}{$2.66(0.10)$} & \multirow[t]{2}{*}{-} \\
\hline & & C & 0.27 & 0.39 & & \\
\hline & \multirow[t]{2}{*}{ rs1465107 } & G & 0.25 & 0.36 & \multirow[t]{2}{*}{$2.3(0.13)$} & \multirow[t]{2}{*}{-} \\
\hline & & $A$ & 0.75 & 0.64 & & \\
\hline & \multirow[t]{2}{*}{ rs1465108 } & $A$ & 0.75 & 0.64 & \multirow[t]{2}{*}{$2.3(0.13)$} & \multirow[t]{2}{*}{-} \\
\hline & & G & 0.25 & 0.36 & & \\
\hline & \multirow[t]{2}{*}{ rs5905809 } & C & 0.28 & 0.39 & \multirow[t]{2}{*}{$2.09(0.15)$} & \multirow[t]{2}{*}{-} \\
\hline & & G & 0.72 & 0.61 & & \\
\hline & \multirow[t]{2}{*}{ rs5906957 } & $A$ & 0.72 & 0.61 & \multirow[t]{2}{*}{$2.09(0.15)$} & \multirow[t]{2}{*}{-} \\
\hline & & G & 0.28 & 0.39 & & \\
\hline & \multirow[t]{2}{*}{ rs6323 } & $T$ & 0.15 & 0.33 & \multirow[t]{2}{*}{$7.22(\mathbf{0 . 0 0 7})$} & \multirow[t]{2}{*}{$1.27(1.06-1.52)$} \\
\hline & & G & 0.85 & 0.67 & & \\
\hline & \multirow[t]{2}{*}{ rs1137070 } & C & 0.25 & 0.40 & \multirow[t]{2}{*}{$3.87(\mathbf{0 . 0 5})$} & \multirow[t]{2}{*}{$1.23(1.00-1.54)$} \\
\hline & & $T$ & 0.75 & 0.60 & & \\
\hline \multirow[t]{14}{*}{$M A O B$} & \multirow[t]{2}{*}{ rs4824562 } & $A$ & 0.83 & 0.81 & \multirow[t]{2}{*}{$0.06(0.81)$} & \multirow[t]{2}{*}{-} \\
\hline & & G & 0.17 & 0.19 & & \\
\hline & \multirow[t]{2}{*}{ rs56220155 } & G & 0.33 & 0.20 & $3.66(0.06)$ & $1.19(1.00-1.44)$ \\
\hline & & $A$ & 0.67 & 0.80 & & \\
\hline & rs2283728 & $T$ & 0.23 & 0.16 & $0.98(0.32)$ & - \\
\hline & & C & 0.77 & 0.84 & & \\
\hline & rs2283727 & C & 0.77 & 0.84 & $0.98(0.32)$ & - \\
\hline & & $A$ & 0.23 & 0.16 & & \\
\hline & rs3027441 & C & 0.25 & 0.15 & $2.51(0.11)$ & - \\
\hline & & $T$ & 0.75 & 0.85 & & \\
\hline & rs6324 & C & 0.75 & 0.85 & $2.51(0.11)$ & - \\
\hline & & $T$ & 0.25 & 0.15 & & \\
\hline & rs3027440 & $T$ & 0.83 & 0.86 & $0.31(0.58)$ & - \\
\hline & & $C$ & 0.17 & 0.14 & & \\
\hline
\end{tabular}


serotonergic system [66, 67], making both the enzymes crucial while studying human behavior.

Several investigators have tried to find out whether $M A O A$ and $M A O B$ confer risk of ADHD using familybased association studies, though the data obtained were inconclusive [31, 44-47, 68]. In the Israeli population, family based association studies revealed significant association of MAOA $30 \mathrm{bp}-\mathrm{uVNTR}$ with ADHD [47]. In the Irish ADHD probands, significantly preferential transmission of $M A O A$ rs6323 ' $G$ ' allele and a haplotype was reported, while $M A O B$ variants failed to exhibit any association [44]. In European Caucasoid subjects from eight different countries, family based study revealed positive association of $M A O A$ with ADHD, while $M A O B$ variants failed to do so [45]. In the Taiwanese ADHD population also, significant over-transmission of $M A O A$ rs6323 ' $G$ ' allele and higher transmission of the ' $3 R-G$ ' (30 bp-uVNTR-rs6323) haplotype was observed [35]. In Caucasian female ADHD probands from USA, a stronger association of $M A O A$ variant was reported by family based study [69]. In the Han Chinese population also, preferential transmission of specific alleles and haplotypes to the probands was reported [46]. In the same population, $M A O A$ polymorphisms were reported to be transmitted to only the male probands having hyperactive/impulsive subtype [70].

On the contrary, in Caucasian ADHD subjects from the United Kingdom, family based association studies found no significant association of $M A O A$ variants with the disorder [31, 71]. A large-scale family based study, recruiting ADHD subjects residing in Ireland and Australia, also failed to identify any significant association of $M A O A$ variants [68]. This reported discrepancy in association of $M A O A$ and $M A O B$ with ADHD could be due to ethnic variations in the frequency of risk variants in the population.

Our earlier investigation on limited number of IndoCaucasoid ADHD probands $(N=73)$ revealed preferential maternal transmission of the $30 \mathrm{bp}-\mathrm{uVNTR}$ ' $3 R$ ' allele to the male probands [34]. A follow up study $(N=126)$ revealed biased transmission of ' $3 R-T$ ' haplotype (30 bp-uVNTR-rs6323) with high relative risk $(8.06 \mathrm{e}+007)$ indicating significant risk of association with ADHD [72]. A later investigation also revealed maternal transmission bias for the ' $3 R-T$ ' haplotype to the male probands [73]. In the present family-based study, analysis was conducted on 58 variants located in the $M A O A$ and $M A O B$ genes. Out of the 58 variants, only 15 were polymorphic in this population. Statistical analysis was conducted on ADHD subjects $(N=190)$ stratified based on gender since $M A O$ genes are located on the Xchromosome and dosage is different in the male probands as compared to the females. Significantly preferential maternal transmissions were observed for $M A O A$ (rs5905809, rs5906957, rs6323) and $M A O B$ (rs56220155, rs2283728, rs2283727, rs3027441, rs6324, rs3027440) variants in the male probands. Maternal transmissions to the male probands were also biased for several haplotypes. The 30 bp-uVNTR ' $3 R$ ' allele, as part of haplotypes with other variants, showed transmission bias in the male probands. This observation provided further support to our earlier notion that the ' $30 \mathrm{bp}-\mathrm{uVNTR} 3 R$ allele' could be a risk factor for ADHD and is maternally transmitted to the male probands. This bias may, at least partly, be responsible for the male preponderance of the disorder. Further, preferential transmission of $M A O A$ and $M A O B$ variants from the mother to the male probands could be responsible for the higher heritability of the disorder, at least in this population. In the female ADHD probands, no such bias in parental transmissions was observed. However, the number of female probands was limited in the present investigation. Further investigation, involving large cohort of subjects from different ethnicity, would help us to elucidate the actual role of MAO in the etiology of ADHD.

In Swedish ADHD probands, the MAOA 30 bpUVNTR '3R' allele showed association with disruptive behavior in boys [74]. Our earlier population based analysis on this group of subjects revealed significant contribution of $M A O A$ rs6323 [48] and $M A O B$ rs56220155 [49] in ADHD associated conduct disorder as well as ODD. The present investigation revealed significant association of $M A O A$ rs6323 and rs1137070 as well as $M A O B$ rs2283728, rs2283727, rs3027441 and rs6324 with behavioral traits of male ADHD probands. It may be inferred on the basis of the information obtained that variants from both MAO genes may contribute to the behavioral traits of ADHD probands warranting further in depth investigation.

This first ever investigation on association between maternal age and $M A O$ gene variants revealed statistically significant association between maternal age at pregnancy ( $\leq 26$ years) and three $M A O A$ variants, 30 bp-uVNTR ' $3 R$ ', rs6323 ' $G$ ', and $\operatorname{rs} 1137070$ ' $T$ ' in the male ADHD probands. Out of these three variants, rs6323 also exhibited transmission bias, association with behavioral problems, formed part of haplotypes and was in strong LD with various variants. On the basis of this observation, it may be concluded that these $M A O A$ variants, with higher occurrence in probands born to younger mothers, may be contributing to the pathophysiology of ADHD.

\section{Limitations of the study}

The major limitation of the present study was the sample size and hence, further in depth analysis on a large cohort of samples belonging to different ethnic groups would help in validation of the present observation. 


\section{Conclusions}

It may be inferred from the data obtained that both $M A O A$ and $M A O B$ gene variants could be considered as risk factors for ADHD in the Indo-Caucasoid population from eastern India. Our study also revealed association of gene variants with behavioral problems often detected in ADHD subjects and thus could be useful for therapeutic intervention of these subjects. Probands with 30 bpUVNTR ' $3 R$ ' allele may not show improvement in behavioral attributes after treatment with MAOA-inhibitor, since they already possess a compensated amount of the enzyme [75].

\section{Additional files}

Additional file 1: The Hardy-Weinberg equilibrium test performed in female subjects. Description: The table summarizes the genotypic distributions and Hardy-Weinberg equilibrium test performed for MAO polymorphic variants in female subjects. (PDF $29 \mathrm{~kb}$ )

Additional file 2: Parental allelic transmission in female ADHD probands. Description: The table summarizes the parental allelic transmission of MAO alleles in female ADHD probands. (PDF $19 \mathrm{~kb}$ )

Additional file 3: Maternal haplotypic transmission to male ADHD probands (only significant data presented). Description: The table summarizes the maternal haplotypic transmission of MAO haplotypes to male ADHD probands. (PDF $37 \mathrm{~kb}$ )

Additional file 4: Maternal haplotypes not-transmitted to male ADHD probands (only significant data presented). Description: The table summarizes the maternal MAO haplotypes not-transmitted to male ADHD probands. (PDF $35 \mathrm{~kb}$ )

Additional file 5: Parental haplotypic transmission to female ADHD probands. Description: The table summarizes the parental haplotypic transmission of MAO haplotypes to female ADHD probands. (PDF $101 \mathrm{~kb}$ )

Additional file 6: Pair-wise Linkage Disequilibrium (LD) pattern of MAO polymorphic variants (analyzed using Haploview 4.2). Description: The table summarizes the $D^{\prime}$ and $r^{2}$ values for pair-wise LD analysis in male probands, mothers of male probands, female probands and parents of female probands. (PDF $67 \mathrm{~kb}$ )

Additional file 7: Analysis of allelic association with CPRS-R 'T scores' for oppositional behavior and PACS scores for conduct problems in male ADHD probands. Description: The table summarizes statistical comparisons between the mean scores and MAO alleles. (PDF $23 \mathrm{~kb}$ )

Additional file 8: Analysis of allelic association with the status of age-ofonset of ADHD in the male probands. Description: The table summarizes statistical comparison of the early and/or late onset of disorder with MAO alleles. (PDF $25 \mathrm{~kb}$ )

\section{Abbreviations}

ADHD: Attention deficit hyperactivity disorder; bp: Base pair; CPRS-R: Revised conners' parents rating scale; DNA: Deoxyribonucleic acid; DSM-IV: Diagnostic and statistical manual of mental disorders-4th edition; HHRR: Haplotype-based haplotype relative risk; IQ: Intelligent quotient; LD: Linkage disequilibrium; MAO: Monoamine oxidase; MAOA: Monoamine oxidase A; MAOB: Monoamine oxidase B; ODD: Oppositional defiant disorder; PACS: Parental account of children's symptoms; PCR: Polymerase chain reaction; PEA: Phenylethylamine; RR: Relative risk or risk ratio; rs: Reference SNP; SNP: Single-nucleotide polymorphism; uVNTR: Upstream variable number of tandem repeats

\section{Funding}

This work was sponsored by grant \# BT/PR14637/MED/30/561/2010 of the Department of Biotechnology, Government of India.

\section{Availability of data and materials}

The genotype data are presented in detail in the Tables and Additional files. Data that do not pertain to individual patients will be freely available from the corresponding author on reasonable request. Any other information will be shared based on the ethical clearance.

\section{Authors' contributions}

AK carried out genotyping, data acquisition, statistical analyses, data interpretation, and drafted the manuscript. RG participated in genotyping and initial analysis. TS collected the data on ADHD probands' maternal age at pregnancy and assisted in analysis. SM collected the data on age-of-onset of ADHD in the probands and assisted in interpretation. ARo and CKP helped in sequence analysis of target sites. SS and ARa recruited the study subjects and provided clinical assessment. KPM, UR and KM conceptualized as well as designed the study and monitored its completion. KM supervised the work, edited and revised the manuscript. All the authors read, helped in revision and approved the final manuscript.

\section{Ethics approval and consent to participate}

Subjects were recruited as part of a research project approved by the Human Ethical Committee of the Institute (2011/04/28) which follows the guidelines of the Indian Council of Medical Research. Informed written consent was obtained from the guardians/caregivers/ adult individuals for participation in the study.

\section{Consent for publication}

Not applicable.

\section{Competing interests}

The authors declare that they have no competing interests.

\section{Publisher's Note}

Springer Nature remains neutral with regard to jurisdictional claims in published maps and institutional affiliations.

\section{Author details}

${ }^{1}$ Manovikas Biomedical Research and Diagnostic Centre, 482, Madudah, Plot: I-24, Sector-J, Manovikas Kendra, E.M. Bypass, Kolkata 700 107, India.

${ }^{2}$ Department of Oncogene Regulation, Chittaranjan National Cancer Institute, 37 S.P. Mukherjee Road, Kolkata 700 026, India. ${ }^{3}$ Department of Psychiatry, Institute of Post Graduate Medical Education \& Research, Kolkata 700 020, India. ${ }^{4}$ CSIR-Indian Institute of Chemical Biology, Laboratory of Clinical \& Experimental Neurosciences, Cell Biology \& Physiology Division, 4, Raja S.C. Mullick Road, Kolkata 700 032, India. ${ }^{5}$ Inter University Centre for Biomedical Research \& Super Specialty Hospital, Mahatma Gandhi University Campus at Thalappady, Rubber Board PO, Kottayam 686 009, Kerala State, India.

Received: 23 May 2017 Accepted: 27 September 2017

Published online: 05 October 2017

\section{References}

1. APA. Diagnostic and statistical manual of mental disorders. 5th ed. Washington, DC: American Psychiatric Association; 2013.

2. Malhi $P$, Singhi $P$. Spectrum of attention deficit hyperactivity disorders in children among referrals to psychology services. Indian Pediatr. 2000;37:1256-60.

3. Ajinkya S, Kaur D, Gursale A, Jadhav P. Prevalence of parent-rated attention deficit hyperactivity disorder and associated parent-related factors in primary school children of Navi Mumbai-a school based study. Indian J Pediatr. 2013:80:207-10.

4. Venkata JA, Panicker AS. Prevalence of attention deficit hyperactivity disorder in primary school children. Indian J Psychiatry. 2013;55:338-42.

5. Davies W. Sex differences in attention deficit hyperactivity disorder: candidate genetic and endocrine mechanisms. Front Neuroendocrinol. 2014:35:331-46.

6. Thomas R, Sanders S, Doust J, Beller E, Glasziou P. Prevalence of attentiondeficit/hyperactivity disorder: a systematic review and meta-analysis. Pediatrics. 2015;135:e994-1001. 
7. Daley D, Birchwood J. ADHD and academic performance: why does ADHD impact on academic performance and what can be done to support ADHD children in the classroom? Child Care Health Dev. 2010;36:455-64.

8. Classi P, Milton D, Ward S, Sarsour K, Johnston J. Social and emotional difficulties in children with $\mathrm{ADHD}$ and the impact on school attendance and healthcare utilization. Child Adolesc Psychiatry Ment Health. 2012;6:33.

9. Booster GD, Dupaul GJ, Eiraldi R, Power TJ. Functional impairments in children with ADHD: unique effects of age and comorbid status. J Atten Disord. 2012;16:179-89.

10. Reinhardt MC, Reinhardt CA. Attention deficit-hyperactivity disorder, comorbidities, and risk situations. J Pediatr. 2013:89:124-30.

11. Faraone SV, Perlis RH, Doyle AE, Smoller JW, Goralnick JJ, Holmgren MA, et al. Molecular genetics of attention-deficit/hyperactivity disorder. Biol Psychiatry. 2005;57:1313-23.

12. Fonseca DJ, Mateus HE, Galvez JM, Forero DA, Talero-Gutierrez C, Velez-vanMeerbeke A. Lack of association of polymorphisms in six candidate genes in colombian adhd patients. Ann Neurosci. 2015;22:217-21.

13. Faraone SV, Bonvicini C, Scassellati C. Biomarkers in the diagnosis of ADHDpromising directions. Curr Psychiatry Rep. 2014;16:497.

14. Li Z, Chang SH, Zhang LY, Gao L, Wang J. Molecular genetic studies of ADHD and its candidate genes: a review. Psychiatry Res. 2014;219:10-24.

15. Martin J, Hamshere ML, Stergiakouli E, O'Donovan MC, Thapar A. Genetic risk for attention-deficit/hyperactivity disorder contributes to neurodevelopmental traits in the general population. Biol Psychiatry. 2014;76:664-71.

16. Schachar R. Genetics of attention deficit hyperactivity disorder (adhd): recent updates and future prospects. Curr Dev Disord Rep. 2014;1:41-9.

17. Banaschewski T, Becker K, Scherag S, Franke B, Coghill D. Molecular genetics of attention-deficit/hyperactivity disorder: an overview. Eur Child Adolesc Psychiatry. 2010;19:237-57.

18. Cortese S. The neurobiology and genetics of attention-deficit/hyperactivity disorder (ADHD): what every clinician should know. Eur J Paediatr Neurol. 2012;16:422-33.

19. Johansen EB, Aase H, Meyer A, Sagvolden T. Attention-deficit/hyperactivity disorder (ADHD) behaviour explained by dysfunctioning reinforcement and extinction processes. Behav Brain Res. 2002;130:37-45.

20. Solanto MV. Dopamine dysfunction in AD/HD: integrating clinical and basic neuroscience research. Behav Brain Res. 2002;130:65-71.

21. Mueller KL, Tomblin JB. Diagnosis of ADHD and its behavioral, neurologic and genetic roots. Top Lang Disord. 2012;32:207-27.

22. Oades RD, Lasky-Su J, Christiansen H, Faraone SV, Sonuga-Barke EJ, Banaschewski T, et al. The influence of serotonin- and other genes on impulsive behavioral aggression and cognitive impulsivity in children with attention-deficit/hyperactivity disorder (ADHD): Findings from a familybased association test (FBAT) analysis. Behav Brain Funct. 2008;4:48.

23. Edmondson DE, Mattevi A, Binda C, Li M, Hubalek F. Structure and mechanism of monoamine oxidase. Curr Med Chem. 2004;11:1983-93.

24. Tipton KF, Boyce S, O'Sullivan J, Davey GP, Healy J. Monoamine oxidases: certainties and uncertainties. Curr Med Chem. 2004;11:1965-82.

25. Bach AW, Lan NC, Johnson DL, Abell CW, Bembenek ME, Kwan SW, et al. cDNA cloning of human liver monoamine oxidase $A$ and $B$ : molecular basis of differences in enzymatic properties. Proc Natl Acad Sci U S A. 1988;85: 4934-8

26. Grimsby J, Chen K, Wang LJ, Lan NC, Shih JC. Human monoamine oxidase $A$ and $B$ genes exhibit identical exon-intron organization. Proc Natl Acad Sci U S A. 1991;88:3637-41.

27. Zhu QS, Grimsby J, Chen K, Shih JC. Promoter organization and activity of human monoamine oxidase (MAO) A and B genes. J Neurosci. 1992;12:4437-46.

28. Brunner HG, Nelen M, Breakefield XO, Ropers HH, van Oost BA. Abnormal behavior associated with a point mutation in the structural gene for monoamine oxidase A. Science. 1993;262:578-80.

29. Alia-Klein N, Goldstein RZ, Kriplani A, Logan J, Tomasi D, Williams B, et al. Brain monoamine oxidase A activity predicts trait aggression. J Neurosci. 2008;28:5099-104.

30. Shih JC, Chen K, Ridd MJ. Monoamine oxidase: from genes to behavior. Annu Rev Neurosci. 1999:22:197-217.

31. Lawson DC, Turic D, Langley K, Pay HM, Govan CF, Norton N, et al. Association analysis of monoamine oxidase $A$ and attention deficit hyperactivity disorder. Am J Med Genet B Neuropsychiatr Genet. 2003;116B:84-9.

32. Trent $S$, Davies $W$. The influence of sex-linked genetic mechanisms on attention and impulsivity. Biol Psychol. 2012;89:1-13.
33. Shiraishi H, Suzuki A, Fukasawa T, Aoshima T, Ujiie Y, Ishii G, et al. Monoamine oxidase A gene promoter polymorphism affects novelty seeking and reward dependence in healthy study participants. Psychiatr Genet. 2006;16:55-8.

34. Das M, Bhowmik AD, Sinha S, Chattopadhyay A, Chaudhuri $K$, Singh $M$, et al. MAOA promoter polymorphism and attention deficit hyperactivity disorder (ADHD) in indian children. Am J Med Genet B Neuropsychiatr Genet. 2006;141B:637-42.

35. Xu X, Brookes K, Chen CK, Huang YS, Wu YY, Asherson P. Association study between the monoamine oxidase A gene and attention deficit hyperactivity disorder in Taiwanese samples. BMC Psychiatry. 2007;7:10.

36. Oreland L, Damberg M, Hallman J, Berggard C, Garpenstrand H. Risk factors for the neurohumoral alterations underlying personality disturbances. Neurotox Res. 2002:4:421-6.

37. Staif $R$, Drtilkova I, Theiner P, Didden W, Pitelova R, Mikes V, et al. Two candidate gene polymorphisms in ADHD children: a case-control study of catechol-O-methyltransferase (COMT) and monoamine oxidase B (MAOB) genes. Arch Med Sci. 2006;2:235-9.

38. Dlugos AM, Palmer AA, de Wit H. Negative emotionality: monoamine oxidase B gene variants modulate personality traits in healthy humans. J Neural Transm. 2009;116:1323-34.

39. Whitfield JB, Pang D, Bucholz KK, Madden PA, Heath AC, Statham DJ, et al. Monoamine oxidase: associations with alcohol dependence, smoking and other measures of psychopathology. Psychol Med. 2000;30:443-54.

40. Lenders JW, Eisenhofer G, Abeling NG, Berger W, Murphy DL, Konings CH, et al. Specific genetic deficiencies of the $A$ and $B$ isoenzymes of monoamine oxidase are characterized by distinct neurochemical and clinical phenotypes. J Clin Invest. 1996;97:1010-9.

41. Cases O, Seif I, Grimsby J, Gaspar P, Chen K, Pournin S, et al. Aggressive behavior and altered amounts of brain serotonin and norepinephrine in mice lacking MAOA. Science. 1995;268:1763-6.

42. Grimsby J, Toth M, Chen K, Kumazawa T, Klaidman L, Adams JD, et al. Increased stress response and beta-phenylethylamine in MAOB-deficient mice. Nat Genet. 1997;17:206-10.

43. Chen K, Holschneider DP, Wu W, Rebrin I, Shih JC. A spontaneous point mutation produces monoamine oxidase A/B knock-out mice with greatly elevated monoamines and anxiety-like behavior. J Biol Chem. 2004;279:39645-52.

44. Domschke K, Sheehan K, Lowe N, Kirley A, Mullins C, O'Sullivan R, et al. Association analysis of the monoamine oxidase $A$ and $B$ genes with attention deficit hyperactivity disorder (ADHD) in an Irish sample: preferential transmission of the MAO-A 941G allele to affected children. Am J Med Genet B Neuropsychiatr Genet. 2005;134B:110-4.

45. Brookes K, Xu X, Chen W, Zhou K, Neale B, Lowe N, et al. The analysis of 51 genes in DSM-IV combined type attention deficit hyperactivity disorder: association signals in DRD4, DAT1 and 16 other genes. Mol Psychiatry. 2006;11:934-53.

46. Li J, Wang Y, Hu S, Zhou R, Yu X, Wang B, et al. The monoamine oxidase B gene exhibits significant association to ADHD. Am J Med Genet B Neuropsychiatr Genet. 2008;147:370-4.

47. Manor I, Tyano S, Mel E, Eisenberg J, Bachner-Melman R, Kotler M, et al. Family-based and association studies of monoamine oxidase $A$ and attention deficit hyperactivity disorder (ADHD): preferential transmission of the long promoter-region repeat and its association with impaired performance on a continuous performance test (TOVA). Mol Psychiatry. 2002;7:626-32.

48. Karmakar A, Maitra S, Verma D, Chakraborti B, Goswami R, Ghosh P, et al. Potential contribution of monoamine oxidase A gene variants in ADHD and behavioral co-morbidities: scenario in eastern Indian probands. Neurochem Res. 2014;39:843-52.

49. Karmakar A, Maitra S, Chakraborti B, Verma D, Sinha S, Mohanakumar KP, et al. Monoamine oxidase B gene variants associated with attention deficit hyperactivity disorder in the Indo-Caucasoid population from West Bengal. BMC Genet. 2016:17:92.

50. APA. Diagnostic and statistical manual of mental disorders. 4th ed. Washington, DC: American Psychiatric Association; 1994.

51. Conners CK, Sitarenios G, Parker JD, Epstein JN. The revised conners' parent rating scale (CPRS-R): factor structure, reliability, and criterion validity. J Abnorm Child Psychol. 1998;26:257-68.

52. Wechsler D. The Wechsler intelligence scale for children. 3rd ed. San Antonio, TX: The Psychological Corporation; 1991.

53. Bharat RJ. AllSH norms on SFB with Indian children. J All India Inst Speech Hear. 1971;2:34-9. 
54. Miller SA, Dykes DD, Polesky HF. A simple salting out procedure for extracting DNA from human nucleated cells. Nucleic Acids Res. 1988;16:1215.

55. Untergasser A, Cutcutache I, Koressaar T, Ye J, Faircloth BC, Remm M, et al. Primer3-new capabilities and interfaces. Nucleic Acids Res. 2012:40:e115.

56. Sanger F, Nicklen S, Coulson AR. DNA sequencing with chain-terminating inhibitors. Proc Natl Acad Sci U S A. 1977;74:5463-7.

57. Rodriguez S, Gaunt TR, Day IN. Hardy-Weinberg equilibrium testing of biological ascertainment for Mendelian randomization studies. Am J Epidemiol. 2009;169:505-14.

58. Terwilliger JD, Ott J. A haplotype-based 'haplotype relative risk' approach to detecting allelic associations. Hum Hered. 1992;42:337-46.

59. Dudbridge F. Likelihood-based association analysis for nuclear families and unrelated subjects with missing genotype data. Hum Hered. 2008;66:87-98.

60. Calculator for confidence intervals of relative risk. http://www.hutchon.net/ confidrr.htm. Accessed 21 Sep 2017

61. Barrett JC, Fry B, Maller J, Daly MJ. Haploview: analysis and visualization of LD and haplotype maps. Bioinformatics. 2005;21:263-5.

62. VassarStats: Website for Statistical Computation. http://vassarstats.net/index html. Accessed 09 Jan 2017.

63. Crockett MJ, Clark L, Hauser MD, Robbins TW. Serotonin selectively influences moral judgment and behavior through effects on harm aversion. Proc Natl Acad Sci U S A. 2010;107:17433-8.

64. Volkow ND, Wang GJ, Maynard L, Jayne M, Fowler JS, Zhu W, et al. Brain dopamine is associated with eating behaviors in humans. Int J Eat Disord. 2003;33:136-42.

65. Egerton A, Mehta MA, Montgomery AJ, Lappin JM, Howes OD, Reeves SJ, et al. The dopaminergic basis of human behaviors: a review of molecular imaging studies. Neurosci Biobehav Rev. 2009;33:1109-32.

66. Oades RD. Dopamine-serotonin interactions in attention-deficit hyperactivity disorder (ADHD). Prog Brain Res. 2008;172:543-65.

67. Seo D, Patrick CJ, Kennealy PJ. Role of serotonin and dopamine system interactions in the neurobiology of impulsive aggression and its comorbidity with other clinical disorders. Aggress Violent Behav. 2008;13:383-95.

68. Hawi Z, Matthews N, Barry E, Kirley A, Wagner J, Wallace RH, et al. A high density linkage disequilibrium mapping in 14 noradrenergic genes: evidence of association between SLC6A2, ADRA1B and ADHD. Psychopharmacology. 2013:225:895-902.

69. Biederman J, Kim JW, Doyle AE, Mick E, Fagerness J, Smoller JW, et al. Sexually dimorphic effects of four genes (COMT, SLC6A2, MAOA, SLC6A4) in genetic associations of ADHD: a preliminary study. Am J Med Genet B Neuropsychiatr Genet. 2008;147B:1511-8.

70. Liu L, Guan LL, Chen Y, Ji N, Li HM, Li ZH, et al. Association analyses of MAOA in Chinese Han subjects with attention-deficit/hyperactivity disorder: family-based association test, case-control study, and quantitative traits of impulsivity. Am J Med Genet B Neuropsychiatr Genet. 2011;156B:737-48.

71. Payton A, Holmes J, Barrett JH, Hever T, Fitzpatrick H, Trumper AL, et al. Examining for association between candidate gene polymorphisms in the dopamine pathway and attention-deficit hyperactivity disorder: a familybased study. Am J Med Genet. 2001;105:464-70.

72. Das M, Das Bhowmik A, Bhaduri N, Sarkar K, Ghosh P, Sinha S, et al. Role of gene-gene/gene-environment interaction in the etiology of eastern Indian ADHD probands. Prog Neuro-Psychopharmacol Biol Psychiatry. 2011;35:577-87.

73. Das Bhowmik A, Sarkar K, Ghosh P, Das M, Bhaduri N, Sarkar K, et al. Significance of dopaminergic gene variants in the male biasness of ADHD. J Atten Disord. 2017;21:200-8.

74. Malmberg K, Wargelius HL, Lichtenstein P, Oreland L, Larsson JO. ADHD and disruptive behavior scores - associations with MAO-A and 5-HTT genes and with platelet MAO-B activity in adolescents. BMC Psychiatry. 2008;8:28.

75. Sabol SZ, Hu S, Hamer D. A functional polymorphism in the monoamine oxidase A gene promoter. Hum Genet. 1998;103:273-9.

\section{Submit your next manuscript to BioMed Central and we will help you at every step:}

- We accept pre-submission inquiries

- Our selector tool helps you to find the most relevant journal

- We provide round the clock customer support

- Convenient online submission

- Thorough peer review

- Inclusion in PubMed and all major indexing services

- Maximum visibility for your research

Submit your manuscript at www.biomedcentral.com/submit
Biomed Central 